This is a pre-copyedited, author-produced version of an article accepted for publication in European Review of Agricultural Economics following peer review. The version of record "Cruz, L; Ramos, P.; Barata, E.; Sargento, A. (2017) “Assessing an Agri-food Development Strategy: A Bi-Regional Input-Output Model with Resource-Constrained Sectors", European Review of Agricultural Economics, 44(5), 860-882" is available online at: https://doi.org/10.1093/erae/jbw028.

European Review of Agricultural Economics Vol 44 (5) (2017) pp. 860-882 doi:10.1093/erae/jbw028

Advance Access Publication 8 May 2017

\title{
Assessing an agri-food development strategy: a bi-regional input-output model with resource-constrained sectors
}

\author{
Luís Cruz ${ }^{*, \dagger}$, Pedro N. Ramos ${ }^{\dagger}$, Eduardo Barata ${ }^{\dagger}$ \\ and Ana L. Sargento \\ ${ }^{\dagger}$ University of Coimbra - GEMF, CeBER and Faculty of Economics, \\ Portugal; ${ }^{\ddagger}$ Polytechnic Institute of Leiria - School of Technology and \\ Management (ESTG), Management for Sustainability Research Centre \\ (CIGS), Portugal
}

Received October 2015; editorial decision December 2016; final version accepted December 2016

Review coordinated by Ada Wossink

\begin{abstract}
Uneven regional development is widely recognised. This paper explores the effectiveness of a regional development strategy based on the agri-food sector expansion in a laggard agriculture dependent region. We use a bi-regional rectangular InputOutput model, explicitly taking into account the methodological and policy implications of resource-constrained products. Results confirm that local transformation of agricultural products has a positive but limited effect, due to land restrictions and impact leaks to the more complex and developed region. The regional development strategy would be more effective if it focuses instead on non-tradable products or not so dependent on natural resources.
\end{abstract}

Keywords: agri-food sector, bi-regional input-output model, resource-constrained modelling

JEL classification: Q18 (Agricultural Policy I Food Policy), R11 (Regional Economic Activity: Growth, Development, Environmental Issues, and Changes), R15 (Econometric and Input-Output Models) 


\section{Introduction}

This is a paper on an asymmetric country, where a less developed region, still relying on exports of primary products, either to abroad or to the rest of the country, in particular "Products of agriculture, animals farming, hunting and related services", coexists with a more industrialized, populated and developed region. The research concerns the definition of a development strategy for the laggard region, aiming to reduce the major regional asymmetry within the national territory. The focus is on a possible exogenous increase in the production of the agri-food industry products supplied in the agriculture dependent region. By agri-food products we mean both manufactured food products and beverages. The new plants, in the laggard region, are deemed to be competitive, and thus a matching increase in the demand for the new products is admitted (e.g., the new products are exportable). ${ }^{1}$ Thus, the main idea underlying this strategy is to shift the export base of the less developed region from primary products, such as the products of agriculture, to agri-food products involving a higher value added, or in other words allowing for an upgrade of the regional value chain (Marsden and Sonnino, 2008; van der Ploeg et al. 2008; Irwin et al., 2010; Martinho, 2015). The purpose of this paper is thus to make an appraisal of this policy.

For this, the methodological and empirical applications are designed to determine the overall effects of a development strategy based on the expansion of the agri-food sector in the rural region of a country, and to assess the separate effects of such a strategy in both regions (although the shock is confined only to one). Will any benefits be limited to the region where the strategy is implemented? Or will the benefits spillover into the more economically powerful region, and if so, to what extent?

To analyse these issues a bi-regional input-output (IO) model is built up, focusing on the interdependencies between the two regions into which the country is split: the laggard rural one and the more developed part of the territory. This model is of the "supply and use" type, which allows for a high level of product detail: in our application 431 products (of which 63 products of agriculture, animals farming, hunting and related services) are produced by 125 industries. The first results point to a positive but relatively low local impact of the proposed strategy, due to the high polarization of the economic effects on the more complex and developed region. This conclusion is consistent with other literature findings (Roberts, 1998, 2000; Hyytiä, 2014; Kilkenny and Partridge, 2009), although some disagreement persists (Lindberg and Hansson, 2009).

\footnotetext{
${ }^{1}$ The discussion on how policymakers are able to induce this new capacity is beyond the scope of this paper (although the granting of some kind of subsidy may be presumed).
} 
However, beyond this analysis addressed to the spillover effects that shift a significant part of the policy benefits to the more developed region, a further potential limitation to the effectiveness of this strategy is also addressed. This limitation stems from the fact that standard IO analysis assumes that all production activities are demand-driven, meaning that factor supplies are perfectly elastic in all sectors and that an increase in demand is sufficient to stimulate increases in output and income because excess capacity throughout the economy is assumed (Kilkenny and Partridge, 2009; Irwin, et al., 2010). However, the agri-food sector might be an exception because it is so heavily dependent on agricultural products and agricultural sectors cannot automatically expand or shrink the amount of land being cultivated in response to increased demand (Hubacek and Sun, 2001; Zhang, 2007). That is to say, the domestic supply of agricultural products is inherently limited by the amount of land available. Therefore, one significant methodological contribution of this study is that it discusses the operation of an input-output model of the supply and use type, where some sectors are producers of resourceconstrained products.

This idea of resource constraints has already been addressed by other studies, also based on IO models, but with distinct aims. Hewings et al. (2005) dealt with a constraint related to the availability of water, computing the reduction in agricultural output and employment that would result from an optimal allocation of water resources throughout the several water-consuming sectors in the economy. But land, conversely to water, is more sector-specific, ${ }^{2}$ implying therefore that the focus of this paper is not on sectorial resources reallocation. de la Torre Udarte et al. (2007) also looked at cropland as the scarce restrained factor, though with the purpose of assessing the expansion of bioenergy production in the US (involving a substitution between agricultural products, from their current use to energy crops). In contrast to these papers, this study does not substitute products produced by the same industry, or industries using the same natural resource, but rather it reallocates the destination of agriculture products, from final demand to intermediate consumption of other sectors - the agri-food industry - that locally add more value to the regional final products.

The paper is organized as follows. Section 2 briefly presents the analytical framework, the methodological approach and the data sources of the proposed bi-regional IO model, which is applied to Portugal, splitting the country into the Interior part of the territory and the Coastal region. Section 3 offers a succinct picture of the regional issue in Portugal, detailing some features of the laggard rural Interior region, and proceeding with a first assessment of the suggested agri-food sector development

\footnotetext{
${ }^{2}$ Some room for reallocation exists, e.g. between agriculture and forestry. However, this substitution possibility is deemed to be more limited given the different aptitudes of soils.
} 
strategy. In Section 4, we introduce and discuss the modelling implications of the proposition that agriculture, which is a crucial supplier for the agri-food industry, may be limited in its output by the availability of resources, especially land. Section 5 examines some alternative strategies to the agrifood proposal, and Section 6 concludes.

\section{Methodology and data}

\subsection{The analytical framework of the bi-regional input-output model}

This paper proposes the use of a bi-regional IO model with a laggard region, which in the case study (Section 3) is the Interior ( $I$ ) of Portugal, and a more developed part of the country - the Coast $(C)$, in the case of Portugal. Note that bi-regional IO models allow for economic shock analysis, which when affecting one of the regions spreads to the other, generating a feedback effect by which economic activity in the second region will eventually, through retro-action, affect the first one.

The proposed model adopts a Supply and Use (rectangular) format (Oosterhaven, 1984; Miller and Blair, 2009: Chapter 5; Sargento et al., 2011). This kind of IO models admits more products than industries producing them (in our case, below: 431 products and 125 industries). In other words, the majority of the industries are producers of several different primary products, and also, very often, of some secondary products (i.e., products that are typically produced as primary products by other industries). The main advantage of this structure is that it minimizes the information loss from official statistics, as this dichotomy products-industries is also adopted by modern National Accounts systems. ${ }^{3}$ It is important to note that the different products have different propensities to import (internationally), and our estimations of inter-regional trade also imply different balances and intensities of trade, even when the products are produced by the same industry. Thus, to keep the detail on all the products (not merging them into a reduced number, equal to the number of industries, as a classic symmetric IO model would require) is an advantage.

Besides the supply and use format, the model is also closed with respect to the consumption of (some) households. In fact, very significantly in laggard regions, at the local level (but also in larger and more developed regions, even if the effect looks more diffuse), a new production, to a large extent, impacts most on households' income. In turn, this augmented income implies an increase in consumption, in part directed to locally produced products. In the IO jargon these effects are known

\footnotetext{
${ }^{3}$ From the 1993 United Nations System of National Accounts (SNA1993) onwards.
} 
as "induced effects", and the closure of the model corresponds to taking them into account. ${ }^{4}$ Moreover, one relevant improvement in our model is the partition of households into two types, according to the age of the head-of-household: households in which the representative family member is aged less than 65 years old (hereafter named $<65$ households) or more than 65 years old (from now on named $>65$ households). The intention is to confine the induced effects of increased income that arises directly from the production process (wages and own account work income, also called "mixed income") to the consumption of households headed by someone aged less than 65. Other households consumption is assumed to be exogenous. Furthermore, the consumption structure of $<65$ households is differentiated from the typical consumption bundle of $>65$ households.

The structure of the bi-regional IO model, considering the two regions in which the empirical study is focused, is presented in Table 1.

\footnotetext{
${ }^{4}$ Crossed induced effects (i.e., impacts on consumption products' demand, addressed to one region, when the households income of the other varies) also exist in multi-regional IO models, as is the case in the one we are proposing.
} 
Table 1. The structure of the multi-sector bi-regional Interior-Coast input-output model

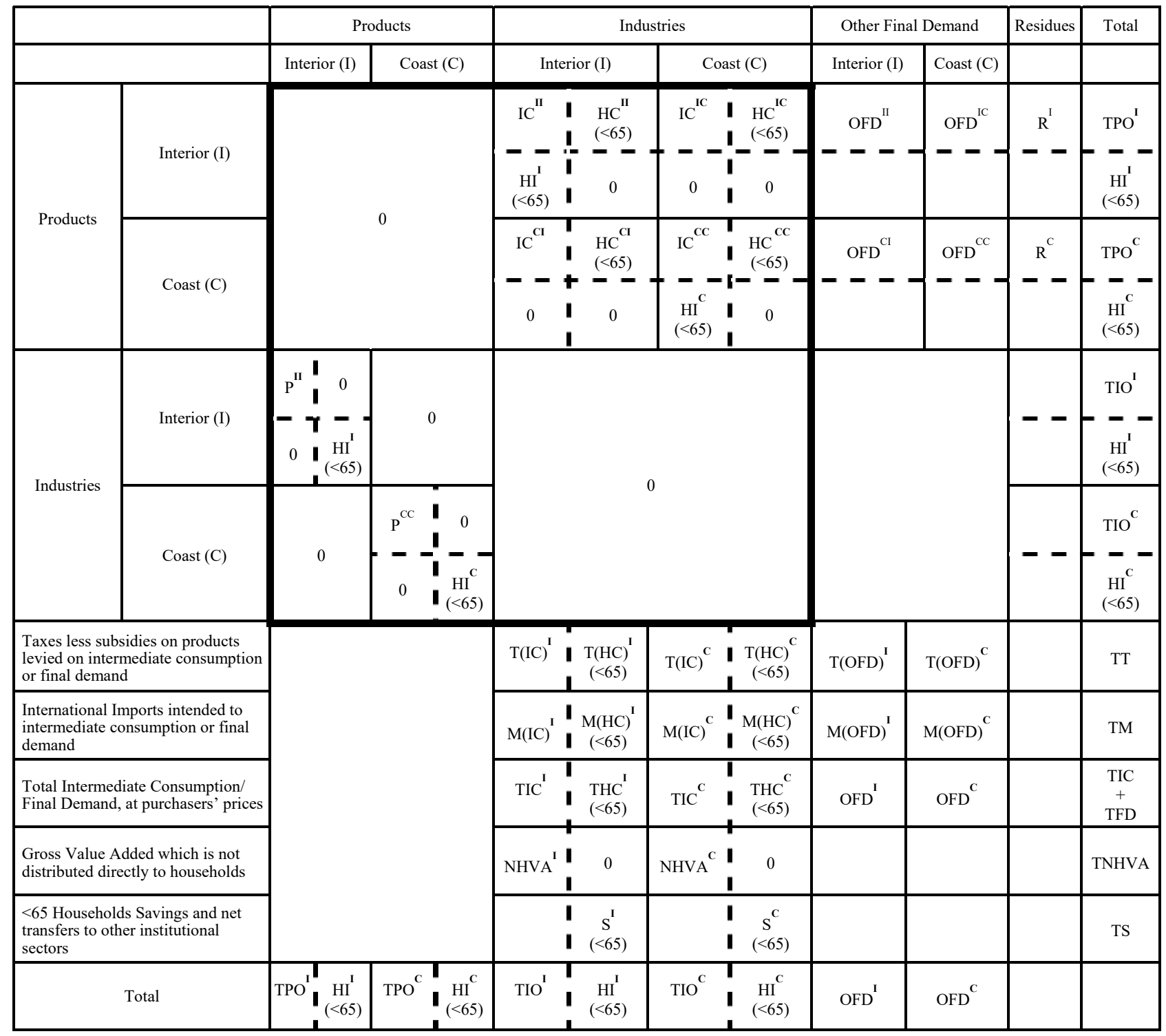

\section{Legend:}

\section{$\boldsymbol{I}$ - Interior \\ C-Coast}

IC $^{\mathrm{ij}} i, j=I, C$ - Intermediate consumption of i's regional products, used by j's industries

$\mathbf{H C}^{\mathrm{ij}}(<\mathbf{6 5}) \quad i, j=I, C$ - Final consumption of i's regional products, consumed by households living in $\mathrm{j}$, in which the representative family member is aged less than 65

OFD $^{\mathrm{ij}} i, j=I, C$ - Other final demand for i's regional products, used in $\mathrm{j}$

$\mathbf{R}^{\mathbf{i}}, \quad i=I, C-$ Residues of the demand for products in region $\mathrm{i}$

$\mathbf{H I}^{\mathbf{i}}(<\mathbf{6 5}) \quad i=I, C$ - region i's $<65$ Households' income (compensation of employees and mixed income)

TPO $^{\mathrm{i}} i=I, C$ - Total output of products produced in region $\mathrm{i}$, at basic prices

$\mathbf{P}^{\mathrm{ii}} i=I, C-\mathrm{i}$ 's regional products, according to the producing industry (generic element of the supply table)

TIO $^{\mathbf{i}} i=I, C-$ region $i^{\prime}$ 's total industry output, at basic prices

$\mathbf{T}(\mathbf{g})^{\mathbf{i}} i=I, C ; g=I C, H C, O F D$ - Taxes (less subsidies) on products falling upon $\mathrm{g}$, in region $\mathrm{i}$

TT - Total taxes less subsidies on products

$\mathbf{M}(\mathbf{g})^{\mathbf{i}} i=I, C ; g=I C, H C, O F D$ - International Imports destined to use $\mathrm{g}$, in region $\mathrm{i}$

TM - Total International Imports 
TIC $^{\mathbf{i}} i=I, C$ - Total intermediate consumption by industries, in region i, at purchasers' prices

THC $\left.^{\text {i }}<\mathbf{6 5}\right) i=I, C$ - Total region i's $<65$ Household consumption, at purchasers' prices

OFD $^{\mathbf{i}} i=I, C-$ Other final demand in region $\mathrm{i}$, at purchasers' prices

TIC + TFD - Total intermediate and final demand, at purchasers' prices

NHVA $^{\mathbf{i}} i=I, C$ - Gross Value Added which is not directly distributed to households, in region $\mathrm{i}$

TNHVA - Total Gross Value Added which is not directly distributed to households

$\mathbf{S}^{\mathbf{i}}(<\mathbf{6 5}) \quad i=I, C-<65$ Household savings and net transfers to other institutional sectors in region i

TS - Total $<65$ Households' savings and net transfers to other institutional sectors

The matrices and vectors within the bold border constitute the core of the model, i.e., the basis for the Leontief Inverse computation. In the case study below, this core part of the matrix has 1116 rows and columns. Reading the "use matrix" (upper right-hand corner of the core part of the table) row-wise, one is informed of the different uses of the 431 products, produced in region $I$ and region $C$, distinguished by type and by location of use: in region $I$ or $C$. The column information in the same sub-matrix concerns the industries. It depicts intermediate consumption in each industry and each region, and distinguishes the regional origin of each input ( $I$ or $C$ ). As the model is closed with respect to $<65$ households, the use matrix also contains the consumption amounts and the income generated by each industry, in each region, which benefits these households. The lower left-hand side of the core table corresponds to the typical "supply table": the rows in matrices $\mathrm{P}^{\mathrm{II}}$ and $\mathrm{P}^{\mathrm{CC}}$ depict the product composition supply of each industry (including both primary and secondary products), in $I$ and $C$, respectively. Households incomes fill one single cell, in each region, in the diagonal of this matrix, for the sake of consistency of the row and column totals of the model.

The structure proposed in Table 1 is of an IO model and therefore it has the advantages (e.g. the great level of detail) and limitations of this type of models. The main limitation is that price variations are not considered, and so they do not play any role in allocating the resources and balancing the markets. All of the resources are deemed to be available up to the level to which they are needed by the (regional and national) economies. Produced inputs expand their supply to meet all of the demand. Unproduced resources (labour, capital, and except for the case addressed in section 4 land) are underemployed, or migrate frictionless from other regions/countries, such that there is always room to increase their use. These assumptions make the IO (mainly) a short-term model. In the following sections, where the focus is on the Portuguese regional division case, the main effects of these assumptions are discussed. 


\subsection{The impacts estimation}

After completion of the bi-regional table, the next purpose is to implement the bi-regional IO model, allowing for the estimation of the regional impacts of different shocks. The table described in the previous section may be written in matricial notation:

$$
\left[\begin{array}{ll}
\mathbf{0} & \mathbf{U} \\
\mathbf{V} & \mathbf{0}
\end{array}\right]+\left[\begin{array}{l}
\mathbf{f} \\
\mathbf{0}
\end{array}\right]=\left[\begin{array}{l}
\mathbf{p} \\
\mathbf{g}
\end{array}\right]
$$

where $\mathbf{U}$ is the "use matrix" and $\mathbf{V}$ the "supply matrix". $\mathbf{f}$ is the column vector of the products' other final demands (it excludes the endogenous consumption of $<65$ households, which was moved into the $\mathbf{U}$ matrix). $\mathbf{p}$ and $\mathbf{g}$ are column vectors representing total product outputs and total industry outputs, respectively.

The first step in the model construction consists then in dividing all the elements of the core part of the matrix, i.e. the sub-matrices $\mathbf{U}$ and $\mathbf{V}$, by the corresponding column totals (given in the bottom row of Table 1), i.e. by $\mathbf{p}$ and $\mathbf{g}$. We get the coefficient matrices $\mathbf{Q}$ and $\mathbf{S}$, computed as follows:

$$
\mathbf{Q}=\mathbf{U} \hat{\mathbf{g}}^{\mathbf{- 1}} \quad \text { and } \quad \mathbf{S}=\mathbf{V} \widehat{\mathbf{p}}^{-\mathbf{1}}
$$

where the ${ }^{\wedge}$ identifies square diagonal matrices, with the cells in their diagonal displaying the same values than the corresponding column vectors $\mathbf{p}$ and $\mathbf{g}$. Given that the model is a bi-regional one, $\mathbf{Q}$ and $\mathbf{S}$ split by regions, with the following structure:

$$
\mathbf{Q}=\left[\begin{array}{ll}
\mathbf{Q}^{\mathrm{II}} & \mathbf{Q}^{\mathrm{IC}} \\
\mathbf{Q}^{\mathrm{CI}} & \mathbf{Q}^{\mathrm{CC}}
\end{array}\right] \text { and } \mathbf{S}=\left[\begin{array}{cc}
\mathbf{S}^{\mathrm{I}} & \mathbf{0} \\
\mathbf{0} & \mathbf{S}^{\mathrm{C}}
\end{array}\right]
$$

with the superscripts $I$ and $C$ referring to the regions, the first one (in the $\mathbf{Q}$ case) to the region of origin of the product (or income), and the second one to the region of use.

The following methodological considerations must also be kept in mind:

- Because of the specific closure of the model, the intermediate consumption matrices (part of $\mathbf{U}$ and then of $\mathbf{Q}$ ) have been extended in each region by an additional column and an additional row. Column $m+1$ in $\mathbf{Q}$ ( $m$ being the number of industries) is composed of $<65$ household consumption coefficients, computed as the division of each product's consumption by the total $<65$ household income. Row $n+1$ (where $n$ is the number of products) in each region represents the labour (and mixed income) input coefficients of that region, derived from the quotient between employees compensations and mixed income received by own account workers in each industry and the 
corresponding total industry output. ${ }^{5}$ The coefficient matrix $\mathbf{Q}$ has then the dimension $2 *(n+1)$ by $2 *(m+1)$.

- Concerning the supply matrix, the division of each element by the column total (total product output) relies on the hypothesis that each industry has its own specific mode of production, irrespective of its product mix (corresponding to the Industry-Based Technology assumption). ${ }^{6} \mathbf{S}$ dimension is $2 *(m+1)$ by $2 *(n+1)$.

The bi-regional IO model can thus be written, in a following step, as a matricial system, which can be solved as follows:

$$
\begin{aligned}
& {\left[\begin{array}{ll}
\mathbf{0} & \mathbf{Q} \\
\mathbf{S} & \mathbf{0}
\end{array}\right]\left[\begin{array}{l}
\mathbf{p} \\
\mathbf{g}
\end{array}\right]+\left[\begin{array}{l}
\mathbf{f} \\
\mathbf{0}
\end{array}\right]=\left[\begin{array}{l}
\mathbf{p} \\
\mathbf{g}
\end{array}\right]} \\
& {\left[\begin{array}{l}
\mathbf{p} \\
\mathbf{g}
\end{array}\right]=\left[\begin{array}{cc}
\mathbf{I} & -\mathbf{Q} \\
-\mathbf{S} & \mathbf{I}
\end{array}\right]^{-1}\left[\begin{array}{l}
\mathbf{f} \\
\mathbf{0}
\end{array}\right]} \\
& {\left[\begin{array}{l}
\mathbf{p} \\
\mathbf{g}
\end{array}\right]=\left[\begin{array}{ll}
\mathbf{D}_{1} & \mathbf{D}_{2} \\
D_{3} & \mathbf{D}_{4}
\end{array}\right]\left[\begin{array}{l}
\mathbf{f} \\
\mathbf{0}
\end{array}\right]}
\end{aligned}
$$

The D-blocks of the inverse matrix have the same dimensions of the sub-matrices above: $\mathbf{D}_{\mathbf{2}}$ of $-\mathbf{Q}, \mathbf{D}_{\mathbf{3}}$ of $-\mathbf{S}$, and $\mathbf{D}_{\mathbf{1}}$ and $\mathbf{D}_{\mathbf{4}}$ of the two identity matrices. $\mathbf{D}$ is the multipliers matrix representing impacts on products' or industries' outputs from demand shocks. For example, $\mathbf{D}_{\mathbf{1}}$ and $\mathbf{D}_{\mathbf{3}}$ give the effects, respectively on products' outputs and industries' outputs of changes in the final demand by products comprised in $\mathbf{f}$. The last rows of both matrices are equal, and provide the impacts on (endogenous) $<65$ households income of shocks on the different products in $\mathbf{f}$. $\mathbf{D}_{\mathbf{2}}$ and $\mathbf{D}_{\mathbf{4}}$ depict the impacts on the same variables of eventual shocks designed at the industries (not the products) level. As the objective in the majority of applications, as in this paper, is to simulate impacts on industries' supplies (g), and related variables, as e.g. GVA and employment, caused by changes in products exogenous final demand (f), $\mathbf{D}_{\mathbf{3}}$ becomes the most important part of $\mathbf{D}$. It should be noted that $\mathbf{D}_{\mathbf{3}}$ can be calculated alone, making use of the partitioned matrices rules (Miller and Blair, 2009: 699-701). Applying these rules we get:

$$
\mathbf{D}_{3}=(\mathbf{I}-\mathbf{S Q})^{-\mathbf{1}} \mathbf{S}
$$

\footnotetext{
${ }^{5}$ In the application developed in this paper, the labour income generated in each region was deemed to be distributed only to households living in the same region. Commuting and other periodical or seasonal migrations between $I$ and $C$, which realistically are negligible between these two regions, were not considered. Releasing this assumption in other bi-regional models is straightforward however, provided that information on commuter workers by industry exists.

${ }^{6}$ An alternative hypothesis, named the Commodity-Based Technology assumption, can also be applied to develop an IO model from the rectangular format. For a detailed discussion, see Miller and Blair (2009: 187-201), Pereira et al. (2011) and Sargento et al. (2011). The adoption of the Industry-Based Technology assumption in Portugal is justified, beyond any discussion on the realism of these assumptions, by the irrelevance of secondary production in the majority of the industries.
} 
Furthermore, when developing this research to the IO model with resource-constrained sectors, $\mathbf{D}_{\mathbf{1}}$ is also used as part of the calculations (see below). $\mathbf{D}_{\mathbf{1}}$ can also be computed alone by:

$$
\mathbf{D}_{\mathbf{1}}=\mathbf{I}+\mathbf{Q}(\mathbf{I}-\mathbf{S Q})^{-\mathbf{1}} \mathbf{S}
$$

\subsection{Regionalization methodology}

The modelling approach presented in the previous sections requires the decomposition of national flows between regions $I$ and $C$. This was undertaken using the MULTI2C (multi-sectoral multi-regional Coimbra model) database. MULTI2C is a general flexible approach, developed by a group of researchers mainly from the University of Coimbra (Portugal) that allows the construction of IO tables for different geographic configurations and empirical applications. Ramos et al. (2015) provide a more detailed description of this general methodology. Here, the 2007 version of the MULTI2C was used, which has a significant level of detail concerning both the number of products it includes (431) and the number of industries (125) that produce them. MULTI2C is carried out on a top-down basis (as done in Lahr (1993), Hulu and Hewings (1993), Barata et al. (2011) and Ramos et al. (2015)). Taking as the starting point the national supply and use table, with the maximum disaggregation, provided by the Portuguese National Accounts, for reference year 2007, the maximum available data of the official Regional Accounts were employed. For Portugal, the available Regional Accounts data comprise the following variables: Total Industry Output, Total Intermediate Consumption at purchasers' prices, and Gross Value Added (including separate knowledge of employees' compensations), for each of the 125 industries and by region.

As a standard, (in the use matrix) the national technology assumption has been adopted, and applied to both regions, for each of the 125 industries. In the current data context, this means that the same structure (for the 431 products) of each industry's intermediate consumption has been considered (since GVA by region is already known). It should also be noted that this equal technology assumption is considered in a "total flow" perspective, i.e., each input is assumed to have the same weight in total intermediate consumption, regardless of the local source of production. Furthermore, the international import propensity for each product is also assumed to be the same in both regions (and thus the same as the national one), irrespective of product use. ${ }^{7}$

Besides this core of National and Regional Accounts information, other regional data sources were used with specific purposes, namely:

\footnotetext{
${ }^{7}$ Except for international exports, for which re-exporting was excluded for the majority of products.
} 
- The estimation of household consumption is based on the Households Expenditure Survey, applied every five years by Statistics Portugal (INE). This survey, together with demographic regional data, enables the estimation of consumption patterns by region and also by the head-of-household age group $(<65$ or $>65$ years old).

- The generic assumption, in the supply matrix, concerning industries' secondary production (which, in most cases, was not significant) is that the weight of secondary products in each industry would be the same in each region, and the same as for the whole country (using National Accounts data). However, regarding primary products, wherever the same industry produces more than one primary product, regionally specific supply-side data were gathered in order to infer the dominant primary products by industry, in each region. This information usually came from employment data based on the Portuguese Ministry of Employment and Social Security database. In the case of agriculture, where one industry corresponds to 63 distinct products, direct information from the 2009 Agricultural Census was used. The National Forestry Survey was also used for the corresponding industry and products. ${ }^{8}$

Interregional trade estimation justifies paying particular attention even in this condensed methodological section, given the usual difficulties associated with this step in any multi-regional IO table construction. The problem is simply that, contrary to the other aggregates, there is no national reference value in national statistics (as consolidated interregional trade is obviously zero when the whole country is taken into account). Miller and Blair (2009: 347-361) have already provided a consistent survey on the ways in which the literature deals with this issue. In fact, in our specific case, the embracement of a bi-regional frame simplified this task. Indeed, in any regional IO model, net interregional exports by region may be estimated through the commodity-balance method: having estimated each product's supply and use components for any given region, the difference between supply and use corresponds to net interregional trade, ${ }^{9}$ and is positive (negative) whenever regional supply is higher (lower) than regional use. Moreover, in a bi-regional model, the net exports of any product by one region are necessarily symmetric to the net imports of the same product by the other region (as long as the estimation methodologies are consistent for both regions). On the other hand, in

\footnotetext{
${ }^{8}$ The specific sources used in estimating the supply matrix provided only initial values that were then further adapted to the 2007 general model resorting to the RAS procedure. In fact, on the one hand, the total production by industry and by region is known from the official Regional Accounts, and on the other, the total production of all products at national level is also known, through the National Accounts. Actually, only the nucleus of the matrix - which region produces each product inside each industry - was missing and was estimated by the RAS. E.g., in the agricultural case, information on cultivated areas by product and on livestock by region, from the Agricultural Census, made up the initial values in the RAS procedure. A standard description of the RAS method can be found in Miller and Blair (2009: 313-332).

${ }^{9}$ In fact, this difference also includes any estimation errors related to either the supply or demand side.
} 
the presence of only two regions that sum up the whole country, it is always true that one region's incountry exports are the other region's in-country imports and vice-versa. Such information about the origin and destination of interregional trade flows is very important in the context of multi-regional IO models, the aim of which is the correct estimation of spillover and feedback effects prompted by any exogenous shock in one of the regions.

Nonetheless, the gross value of interregional imports (and, as a consequence, interregional exports) cannot be estimated immediately, even in a simpler bi-regional IO model. The typical regional IO impact analysis is designed to estimate the local effect of any given final demand change. This depends on the degree of local provision in each transaction flow resulting from the exogenous shock. This means that gross imports (either international or interregional) must be known so that they can be removed from the local impact analysis. In other words, we have to solve what is usually called the cross-hauling problem (Robison and Miller, 1988; Jackson, 1998; Polenske and Hewings, 2004; Kronenberg, 2009; Llano et. al., 2010).

Our approach to estimating gross interregional imports involved the prior classification of all 431 products (that in some cases may not be the same in both regions), depending on an appraisal of the tradability degree of each product, and the adoption of different local source coefficients by product type ${ }^{10}$ Actually, most products can be included in one of two extreme categories for which estimating interregional gross imports is straightforward:

- Type A products are regionally non-tradable, i.e., they are products that must be produced in the region where they are consumed, and therefore are not imported from other regions (or from other countries). Examples include: building construction, retail trade (except fuel) margins, general government services, education and certain personal services. For products in this category, interregional imports were assumed to be null in both regions (consequently, there are no interregional exports, either). In other words, the regional intermediate or final demand flow is assumed to be entirely met by regional source production.

- Tyре B products are fully tradable, internationally and interregionally, i.e., they are products that move between regions at no (or non-significant) cost within a small country like Portugal. In this case there is no valid reason for any regional preference and the following is proposed: the proportion of local supply is assumed to be the same as the regional output weight of that product

\footnotetext{
${ }^{10}$ A similar approach was adopted in Barata et al. (2011) to estimate gross interregional imports in the context of single region models for small regions belonging to the Portuguese Interior, and detailed in Ramos et al. (2015) already in a biregional model context.
} 
in the national total. Given the relative weight of each region in the national output, in most cases $C$ is almost self-sufficient and supplies a high percentage of I's demand. Most manufacturing products fall into this category.

However, there are exceptions to this binary classification. Some products (not many, but with significant transaction amounts) fall into an intermediate category:

- Type $C$ products are regionally tradable under specific conditions for several reasons, one being the high shipping cost, leading to trade only between neighbouring areas. Another interesting situation leads to classifying some other products as type C. This results from the "headquarters effect" (Ramos et al., 2013, 2015). Although the demand for some services is local, it is met by nationwide companies that, for reasons of internal organization, have a significant part of their business located in the national or regional headquarters, which do not tend to be located in the Interior region of Portugal. Although this is essentially local demand matched by a locally provided supply, a significant part of production actually occurs in big coastal cities, which is equivalent to importing a fraction of the total product output from this region $(C)$. Examples of the "headquarters effect" include financial intermediation, and postal and telecommunications services, as well as some other services provided mainly to businesses. In these cases, a detailed analysis was carried out at the NUTS III level, leading to the conclusion that production is concentrated in a few NUTS III regions, which are deemed to be exporting these services to the other regions. Finally, the majority of agricultural products, wholesale trade, transportation services and some specific industrial products are also treated as type $C$ products, with a basic assumption being a minimum local source provision of $50 \%$, plus a percentage equal to the region's weight in the national output of the same product. ${ }^{11}$

This methodology produced a first estimate of gross interregional imports by product for the two regions. Interregional gross exports were computed by adding up interregional gross imports and the previously known interregional net trade. Yet, even if net trade is symmetric between the two regions, this method does not imply that the estimated gross imports for one region mirror the estimated gross exports of the other. Hence, a final consistency adjustment was made to guarantee that coincidence: increasing the interregional exports and imports of one region while decreasing the interregional exports and imports of the other region, until the gross exports of one matched the gross imports of the other, for each product. The adjustment in each region was distributed while taking into account its relative weight in the product's output.

\footnotetext{
11 This ad-hoc percentage was subjected to a sensitivity analysis, reducing it to $30 \%$ and $40 \%$, and increasing it to $60 \%$ and 70\%. Overall "macro" results are relatively robust to that analysis (Ramos et al., 2013).
} 


\section{The Interior region of Portugal and the agri-food development strategy}

The regional asymmetries within the Portuguese economy are essentially between the Coast (shoreline) and the Interior (inland) regions of the country. More specifically, the Interior suffers from a recognized relative backwardness, which is at the heart of the public debate regarding Portuguese regional policy. Though occupying 57\% of Portuguese territory, its population is only about $15 \%$ of the country's total, and its economic activity amounts to only $11 \%$ of the Portuguese GDP. The Interior and Coast regions ( $I$ and $C$, respectively) are geographically defined in this paper as in Figure 1, using an aggregation of the NUTS III regions. As these two regions do not coincide with the official NUTS II map, it is relatively uncommon to discuss regional contrasts with this configuration in Portuguese regional science. Table A1 in the Annex, in its two first columns, gives some further detail on the sectoral structure of both regions, $I$ and $C$.

Figure 1. Interior and Coast regions in Portugal

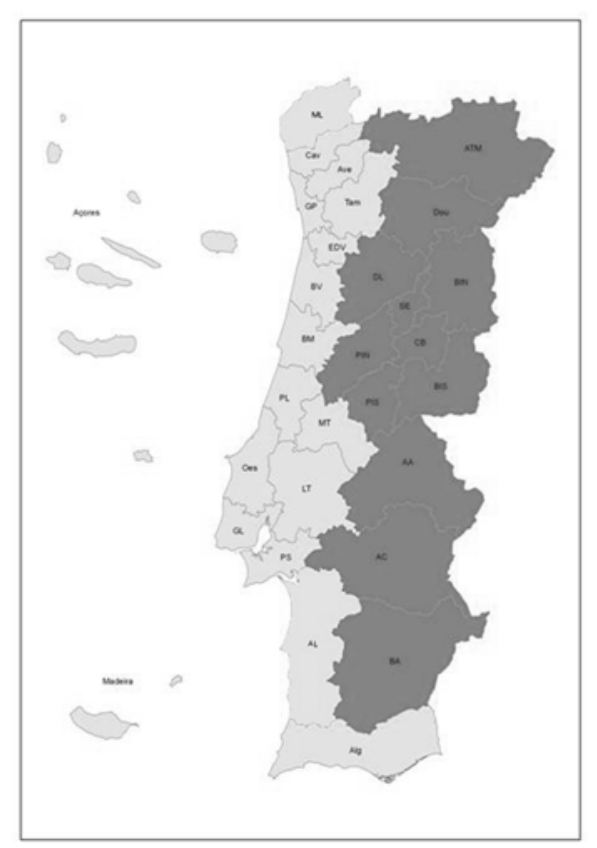

It is worth mentioning that $I$ still represents 1.6 million inhabitants. This is a paper on a rural region, not on a rural community. $I$ is said to be rural due to its dependence on primary products, in a country with reduced agricultural aptitude. However, I comprises several middle-sized urban centres (where realistically agri-food plants are supposed to be located). In spite of this focus on a region, this 
paper shares with rural communities IO models (Robison, 1997; Robison and Lahr, 1997) the recognition of the great openness of rural economies.

It is also notable that the $I$ population has a much higher percentage of persons over 65 . According to the 2011 Census data, $25.8 \%$ of the interior's population is over 65, compared with $18.8 \%$ in the coastal region. Furthermore, the population below 25 represents only $22.6 \%$ of the population in $I$, against $26.3 \%$ in $C$. The demographic ageing of $I$ is due to persistent migration to $C$ or abroad, especially by younger adults. Significantly, since the 1980s the emigration of young adults from $I$ has tended to be offset by the immigration of older age groups, presumably as a result of the return of migrants. However, despite the relative migratory equilibrium, the $I$ population has continued to decline sharply, since being older the birth rate is lower and the mortality higher, and the natural balance is strongly negative (Ramos et al., 2011; Martins et al., 2013).

The primary purpose of applying our bi-regional model is to analyse the impacts on regions $I$ and $C$ of shocks occurring in either of these territories. But it also has the virtue of allowing a highly detailed, multi-sector, characterization of the two regional economies. In particular, the estimation of interregional trade undertaken in the modelling process is valuable in itself, as it allows an analysis of the (regional and international) trade balance of the regions, and their economic base. Table 2 highlights the major export products of region $I$, in terms of both gross exports and exports less imports.

Table 2. Main international and interregional exports (in gross and net terms) from the Interior region of Portugal

\begin{tabular}{|c|c|c|c|}
\hline unit: $10^{6} €(2007)$ & $\begin{array}{c}\text { Gross } \\
\text { Exports } \\
\end{array}$ & & $\begin{array}{c}\text { Exports less } \\
\text { Imports } \\
\end{array}$ \\
\hline $\begin{array}{l}\text { Products of agriculture, animals } \\
\text { farming, hunting and related } \\
\text { services }\end{array}$ & 1243.8 & $\begin{array}{l}\text { Products of agriculture, animals } \\
\text { farming, hunting and related } \\
\text { services }\end{array}$ & 554.1 \\
\hline $\begin{array}{l}\text { Manufactured food products } \\
\text { (except beverages) }\end{array}$ & 1169.3 & Metal Ores & 471.2 \\
\hline $\begin{array}{l}\text { Motor vehicles, trailers and } \\
\text { semi-trailers }\end{array}$ & 961.6 & $\begin{array}{l}\text { Land transport (including via } \\
\text { pipelines) services }\end{array}$ & 407.4 \\
\hline $\begin{array}{l}\text { Food and beverage services } \\
\text { (restaurants activity) }\end{array}$ & 742.8 & Beverages & 362.4 \\
\hline $\begin{array}{l}\text { Electricity, gas, steam, cold and } \\
\text { hot water and cold air }\end{array}$ & 640.7 & $\begin{array}{l}\text { Wood and cork products, } \\
\text { except furniture }\end{array}$ & 326.5 \\
\hline
\end{tabular}

One noteworthy fact that is revealed in Table 2 is the still enormous dependence of region $I$ upon exports of products from agriculture and animals farming. This finding is relatively unexpected, especially because Portugal as a whole is a country with a small agricultural capacity and a huge 
national trade deficit in agricultural products. In Portugal, the agriculture sector, which is mainly located in $I$, is characterized by poor labour productivity, thus contributing to the weak economy of this region. Of course, exports of products from agriculture and animals farming in $I$ are delivered mainly to $C$, and only rarely exported abroad. Note, too, that manufactured food products (except beverages) are also an important product in region $I$ exports, but in this case, contrary to products of agriculture, imports exceed exports and there is a negative trade balance. Beverages, however, enjoy a positive trade balance in region $I$, as they include wine, a product with a significant relative weight for both $I$ and the overall Portuguese economy. The enormous dependence of $I$ on agriculture suggests a strategy of incentive to the local transformation, whereby many of the region's commodity products become manufactured food products, including beverages, a composite aggregate that in this paper we call "agri-food products". The idea would be to shift the exporter base of $I$ from primary "products from agriculture" to these "agri-food products", which would involve a higher value-added and encourage labour productivity growth in this region.

Table 3 portrays this scenario for development of the agri-food sector in $I$, and estimates the impact of an (hypothetical) increase in demand for/production of these products to be worth EUR 10 million (as IO are linear models, other shocks can be calculated proportionally), directed exclusively to the $I$ economy. Any compensatory reduction of the production capacity in $C$ for the same products was considered. Table 3 breaks down the total effects of this simulation: direct effects (including not only the shock impact on the production of agri-food products, but also the first wave effects on all of the other inputs used directly in their production ${ }^{12}$ ), indirect effects (the second and following waves of inputs required to produce the inputs used directly in the agri-food industry), and, finally, induced effects (products required to satisfy, in the form of final consumption, the additional of income enjoyed by households where the head is younger than 65).

\footnotetext{
12 This is why the direct effects do not concentrate exclusively on $I$.
} 
Table 3. Economic impacts from a EUR 10 million increase in exogenous final demand for agri-food products, and their production, in the Interior region of Portugal

\begin{tabular}{|c|c|c|c|c|c|c|c|c|}
\hline $\begin{array}{l}\text { unit: } 10^{6} € \text { and } \\
\text { n. employees (2007) }\end{array}$ & $\begin{array}{c}\text { Direct } \\
\text { effect }\end{array}$ & $\%$ & $\begin{array}{c}\text { Indirect } \\
\text { effect }\end{array}$ & $\%$ & $\begin{array}{c}\text { Induced } \\
\text { effect }\end{array}$ & $\%$ & $\begin{array}{l}\text { Total } \\
\text { effect }\end{array}$ & $\%$ \\
\hline Output & 16.0378 & & 4.9079 & & 6.8669 & & 27.8126 & \\
\hline Interior & 12.9216 & $80.6 \%$ & 1.0378 & $21.1 \%$ & 2.1253 & $31.0 \%$ & 16.0848 & $57.8 \%$ \\
\hline Coast & 3.1161 & $19.4 \%$ & 3.8701 & $78.9 \%$ & 4.7416 & $69.0 \%$ & 11.7278 & $42.2 \%$ \\
\hline GVA & 4.6431 & & 1.7586 & & 3.5051 & & 9.9069 & \\
\hline Interior & 3.6226 & $78.0 \%$ & 0.4751 & $27.0 \%$ & 1.3386 & $38.2 \%$ & 5.4362 & $54.9 \%$ \\
\hline Coast & 1.0206 & $22.0 \%$ & 1.2836 & $73.0 \%$ & 2.1665 & $61.8 \%$ & 4.4707 & $45.1 \%$ \\
\hline <65 Households Inc. & 4.1817 & & 1.3325 & & 2.5322 & & 8.0464 & \\
\hline Interior & 3.1675 & $75.7 \%$ & 0.4234 & $31.8 \%$ & 1.0455 & $41.3 \%$ & 4.6364 & $57.6 \%$ \\
\hline Coast & 1.0142 & $24.3 \%$ & 0.9091 & $68.2 \%$ & 1.4867 & $58.7 \%$ & 3.4100 & $42.4 \%$ \\
\hline Employment & 412.4 & & 88.4 & & 117.0 & & 617.9 & \\
\hline Interior & 330.4 & $80.1 \%$ & 39.3 & $44.4 \%$ & 48.9 & $41.8 \%$ & 418.6 & $67.8 \%$ \\
\hline Coast & 81.9 & $19.9 \%$ & 49.2 & $55.6 \%$ & 68.1 & $58.2 \%$ & 199.2 & $32.2 \%$ \\
\hline
\end{tabular}

According to the results in Table 3, the multiplier effect on the national economy, from an injection of EUR 10 million into the Interior's agri-food industry, has a sound value of approximately 2.8. But what is remarkable in these calculations is that a significant part of the impact on the output (more than $42 \%$ ) spills over to $C$. Therefore, the ability of $I$ to retain the benefits of a shock to its exogenous demand and own production is comparatively weak. Also concerning the GVA and households income $(<65)$, I's ability to capture the stimulus benefit does not reach even $60 \%$ of the total effects.

The reason why region $I$ can only take relatively small advantage of agri-food expansion in its own territory is the high degree of overspill of the indirect and induced effects into the economy of $C$ (similarly: Roberts (2000) points out the limited ability of a North East Scotland rural area for retaining the benefits of increased local activity; Hyytiä (2014) identifies two Finish regions (rural - urban) where positive effects on regional GDP and employment tend to accumulate in the urban centres). The direct effect is naturally mostly felt in $I$, since this is where the shock takes place. But this impact is offset by the fact that the inputs needed to produce both the agri-food products and the inputs themselves, as well as the extra consumer goods needed because of increased households income, are almost without exception produced in $C$, where the majority of non-agricultural economic activities are concentrated. Table A1 in the Annex sheds some further light on the sectoral composition of the 
shock's effect. The dominance of agri-food products in the local effect - inside $I$ - is quite evident. Beyond the initial impact, non-tradable products play a significant role.

It should be noted that the inability of region $I$ to efficiently capture the indirect and induced effects prompted by an increase in agri-food production does not stem from the region's inability to supply primary agricultural products in favour of local needs. Actually, the Portuguese economy under-produces some agricultural products or does not produce them at all, and therefore any agri-food expansion in $I$ (as would also happen in $C$ ) implies a relatively significant increase in the international import of such products. But regarding national agricultural production overall, the results are quite different. Of the 60 agricultural products produced in Portugal that are considered in our model, I meets more than $70 \%$ of its own national demand for 27 products and more than $50 \%$ for 48 products.

On the other hand, the results in Table 3 have been achieved under the standard assumptions of the IO model, namely fixed price of inputs, and therefore no retroaction on quantities of price variations. If we release these assumptions we may expect higher prices for agricultural products in $I$, and for other inputs used in the production of agri-food. The result should be a reinforced shift of the triggered demand to $C$, and still a higher concentration of the indirect and induced effects in this latter region.

\section{Agriculture as a sector constrained by availability of resources (land)}

However, when an agri-food development strategy in a rural region is proposed, as for region I of Portugal, the argument is not exactly that an increase in production by this sector can and actually will lead to increased agricultural production, as was assumed in the previous section. In fact, the subsumed idea is that the available quantity of agricultural products is limited, and therefore it is preferable to transform them locally, namely using them in the production of agri-food sector, generating more value added, instead of selling them to the rest of the country, or abroad, as primary products. Indeed, the availability of agricultural products is especially constrained by the availability of natural resources needed to produce them, including land. Agriculture is therefore a resourceconstrained sector.

Within the framework of a supply and use model, the assumption of resource-constrained industries and resource-constrained products is not a problem to be solved straight away. In this case, our methodological option is to consider that for the 60 nationally produced "agriculture, animals farming, hunting and related services" products (3 agricultural products are fully imported from 
abroad), the production in $I$ will not exceed in real terms its value in the reference year of 2007. Of course, this must be seen as an extreme hypothesis. On the one hand, some productive land (and/or other specific resources) may still be available and can be used to increment agricultural production. Furthermore, if prices are allowed to vary it may be affordable to mobilize some unused less productive land, or it may be profitable to divert some land from other uses (e.g. forestry); also in the medium term new technological solutions may substitute land by other factors, for example capital. In all of these cases agriculture production can be expanded beyond the 2007 values, though on a moderate scale, compared to the results in section 3.

Thus, when we assume that agriculture production is constrained to a fixed value (or to a small variation), the increase in intermediate demand for these products caused by the expansion of the agrifood sector in I must be offset by fewer uses in the region's final demand, in particular for international exports or sales to $C$. For some products this may even result in a final demand deficit. In other words, the region may be forced to import these products in order to supply the newly emerging manufacturing sector.

In formal terms, our approach follows the mixed exogenous-endogenous models (Miller and Blair, 2009: 621-633), adapted to models of the rectangular type. We assume that there is a variation in final demand $\Delta \mathbf{f}_{0}$, which is confined here to an increased final demand for agri-food products exclusively in $I$. The increase in domestic production of products in both regions can be calculated by:

$$
\Delta \mathbf{p}_{0}=\mathbf{D}_{1} \cdot \Delta \mathbf{f}_{0}
$$

(where $\mathbf{D}_{\mathbf{1}}$ gives the impacts on the products' outputs $\mathbf{p}$ of a shock on products' final demand $\mathbf{f}$ ).

Let $\mathbf{p}^{*}$ be a sub-set of products contained in the vector $\mathbf{p}$, whose production is constrained by the availability of resources, i.e., $\Delta \mathbf{p}^{*}=0$ necessarily. Let $\mathbf{D}_{\mathbf{1}}^{*}$ be an array composed of the rows and columns of $\mathbf{D}_{\mathbf{1}}$ corresponding to the resource-constrained products contained in the sub-vector $\mathbf{p}^{*}$. The problem is that in the sequence of $\Delta \mathbf{f}_{\mathbf{0}}$, there is $\Delta \mathbf{p}_{\mathbf{0}}^{*}>0$, which is part of the vector $\Delta \mathbf{p}_{\mathbf{0}}$ calculated by (7). The $\Delta \mathbf{p}_{\mathbf{0}}^{*}$ must be nullified through a corresponding reduction in final demand $\mathbf{f}^{*}$, addressed to resource-constrained products. The offsetting value of $\mathbf{f}^{*}$ may be compiled by:

$$
\left(-\Delta \mathbf{f}^{*}\right)=\mathbf{D}_{1}^{*-1} \cdot\left(-\Delta \mathbf{p}_{0}^{*}\right)
$$

The final step is to build a vector $\Delta \mathbf{f}$, containing the variation of final demand arising from the exogenous shock (in our case, the demand expansion for agri-food products), and also comprising the vector $\left(-\mathbf{\Delta} \mathbf{f}^{*}\right)$, composed of the compensatory reduction in the resource-constrained products' (in our case agricultural products) final demand. 


$$
\Delta \mathbf{f}=\left[\begin{array}{c}
\left(-\Delta \mathbf{f}^{*}\right) \\
\cdots \\
\mathbf{0} \\
\cdots \\
\Delta \mathbf{f}_{\mathbf{0}} \\
\cdots \\
\mathbf{0}
\end{array}\right]
$$

In the end, the output variation in the economy, by industry, can be calculated by:

$$
\Delta \mathbf{g}=\mathbf{D}_{3} \cdot \Delta \mathbf{f}
$$

(where multipliers $\mathbf{D}_{\mathbf{3}}$ are the impacts on industries' outputs $\mathbf{g}$ of changes in products' final demand $\mathbf{f}$ ).

Table 4 shows the impact of the assumed EUR 10 million capacity and demand increase in agri-food products, including beverages, on the total output in the two regions, and on their GVA, $<65$ households income, and employment. Now, however, this shock is restricted by the non-availability of additional resources needed to produce more agricultural products in $I$, whose output variation is therefore exactly 0 .

Table 4. Economic impact of EUR 10 million increase in exogenous final demand for agri-food products, and their production, in the Interior region of Portugal, constrained by a null variation in agricultural products in the same region

\begin{tabular}{lccccc}
\hline $\begin{array}{l}\text { unit: } 10^{6} \boldsymbol{\epsilon} \text { and } \\
\text { n. employees (2007) }\end{array}$ & Interior & $\mathbf{\%}$ & Coast & $\%$ & $\begin{array}{c}\text { Total } \\
\text { Effect }\end{array}$ \\
\hline Output & 13.2523 & $\mathbf{5 7 . 8 \%}$ & 9.6566 & $\mathbf{4 2 . 2 \%}$ & 22.9088 \\
\hline GVA & 4.1198 & $\mathbf{5 2 . 5 \%}$ & 3.7314 & $\mathbf{4 7 . 5 \%}$ & 7.8512 \\
\hline$<\mathbf{6 5}$ Households Inc. & 3.0502 & $\mathbf{5 1 . 3 \%}$ & 2.8947 & $\mathbf{4 8 . 7 \%}$ & 5.9449 \\
\hline Employment & 232.1 & $\mathbf{5 7 . 4 \%}$ & 172.4 & $\mathbf{4 2 . 6 \%}$ & 404.5 \\
\hline
\end{tabular}

As one might expect, this change in the use of agricultural products from exports (or other final demand destinations) as primary products to their use for intermediate consumption in the $I$ economy, in particular for agri-food industry production, has a positive effect on the economy, and increases the GVA of this region. But it is also clear that this impact is relatively small. The limited availability of resources is an active constraint, which restricts the ability of the economy to expand as a whole and in $I$ in particular. Table 4 shows that the impacts on the different variables are now much lower than those in (the right-hand side of) Table 3, when agricultural production was able to grow freely in reaction to increased production of agri-food products. Clearly, if the constraint were not so binding 
(our calculations were based on an extreme hypothesis), the ability to expand the economy of I might have been higher. ${ }^{13}$

\section{Alternative strategies to the development of the agri-food industry}

This analysis supports the argument that for regions like $I$, a development strategy based on developing an agri-food industry will have limited effectiveness for two main reasons:

- the indirect and induced effects arising from increased demand for these products would mainly spillover into region $C$, the dominant region in terms of economic activity.

- the limited natural resources, especially land, would prevent (or at least mitigate) the expansion of agricultural production in $I$, and thus constrain the pulling impact on this region from the growth of production and demand for agri-food products.

According to these arguments, a region like $I$ should consider alternative strategies involving different types of products, in particular regionally non-tradable products (type A, in the terminology of Section 2.3), or products that are intensive users of inputs with these characteristics. Additionally, these products should not be critically dependent on scarce resources in the $I$ economy.

An example of such a product is "education services". The fact that education services make a decisive contribution in stimulating regional economies has been widely recognized (Pastor et al., 2015). As an illustration, Table 5 gives the results of a simulation of EUR 10 million final demand exogenous growth for "education services" and its impact in $I$.

Table 5. Economic impact from EUR 10 million increase in exogenous final demand and production of education services in the Interior region of Portugal

\begin{tabular}{lrrrrr}
\hline $\begin{array}{l}\text { unit: } \mathbf{1 0}^{6} \boldsymbol{\epsilon} \text { and } \\
\text { n. employees (2007) }\end{array}$ & Interior & $\%$ & Coast & $\%$ & $\begin{array}{r}\text { Total } \\
\text { effect }\end{array}$ \\
\hline Output & 16.0346 & $\mathbf{6 9 . 5 \%}$ & 7.0366 & $30.5 \%$ & 23.0712 \\
\hline GVA & 12.7184 & $\mathbf{8 1 . 3 \%}$ & 2.9318 & $\mathbf{1 8 . 7 \%}$ & 15.6502 \\
\hline$<\mathbf{6 5}$ Households Inc. & 12.1005 & $\mathbf{8 6 . 4 \%}$ & 1.9101 & $\mathbf{1 3 . 6 \%}$ & 14.0106 \\
\hline Employment & 432.4 & $\mathbf{8 2 . 2 \%}$ & 93.6 & $\mathbf{1 7 . 8 \%}$ & 526.0 \\
\hline
\end{tabular}

The results in Table 5 confirm that this strategy has a greater impact than the agri-food strategy, especially in terms of its effect on GVA and on the income of $<65$ households, even if, as assumed in

\footnotetext{
${ }^{13}$ Table A, in the Annex, gives the sectoral composition of the shock effects, on both regions.
} 
Section 3, resource limitations to agricultural production are not taken into account. Additionally, comparing the total impact on $I$ and on $C$, region $I$ now enjoys a much better outcome. Consistent with these findings, Kilkenny and Partridge (2009) argue that 'boost service sectors would enhance rural development more successfully than traditional export-driven manufacturing' (Hyytiä and Kola, 2013: $723)$.

However, the main problem with this strategy lies in its policy feasibility. Indeed, how can one argue for exogenously increasing the demand for education services in $I$ when this region's average age is so high and when the public sector in Portugal is faced with a severe budget constraint? This same problem arises for other non-tradable products, especially those whose main target is public consumption, such as public administration services. Indeed, the relative advantage of implementing policies based on the development of natural resource intensive sectors, such as the agri-food strategy, for regions like $I$, might not lie in the strength of their hauling effects, which are limited, but rather in the creation of more opportunities to market new products, thereby stimulating an effective change in the level of final demand (even if the focus of this paper is on the effectiveness of policies, not on their design). At the end of the day, final-demand shocks do not come from heaven; they have to be based on feasible policy, in the context of market conditions. Moreover, resource-intensive products specific to certain regions are potentially more marketable, in that such regional specificity can be linked to the perception that those products are of better quality and truly genuine.

Finally, an additional, pragmatic, policy approach suited to region $I$ can be suggested. As explained in Section 3, this region has benefited from a significant inflow of older people, assumed to correspond mostly to the return of former migrants (for a discussion on the potential role of in-migrant households in rural areas, particularly associated with their income sources and consumption structures, see Roberts, 2005). Accordingly, the impacts presented in Table 6 assume a strengthening of this trend and posit an additional EUR 10 million consumption by $I^{\text {'s }}>65$ households, with an equivalent reduction in such consumption in region $C$. 
Table 6. Economic impact from a EUR 10 million shift in the exogenous final consumption of $>65$ households from the Coast to the Interior region of Portugal

\begin{tabular}{lcr}
\hline $\begin{array}{l}\text { unit: } 10^{6} € \text { and } \\
\text { n. employees (2007) }\end{array}$ & Interior & \multicolumn{1}{c}{ Coast } \\
\hline Output & 10.0462 & -10.9385 \\
\hline GVA & 6.6411 & -6.4471 \\
\hline$<$ 65 Households Inc. & 5.2832 & -5.0411 \\
\hline Employment & 224.4 & -202.3 \\
\hline
\end{tabular}

It is important to stress that the shock contemplated in the construction of Table 6 is different in nature from the others considered here. In fact, this is not a national shock that would result in greater demand within the Portuguese economy as a whole; it is simply a shift in demand from $C$ to $I$. I's economy expands, but C's contracts. Still, the notably positive impacts both on the GVA and on the income of younger households headed by an under-65-year-old in region $I$ exceed those derived from the development of the agri-food sector. The main reason for this is the significant consumption of personal, non-tradable services by these older families that return to region $I$.

\section{Conclusions}

The unequal development of more urban and mainly rural regions has been a reality for many years in Portugal and elsewhere in the world, and policies not adjusted to this reality tend to increase these asymmetries. Based on a bi-regional rectangular (supply and use) IO model empirically applied to Portugal, with a significant degree of detail (431 products; 125 industries), this paper evaluates the effectiveness and the benefits and drawbacks of a development policy based on the agri-food industry (manufactured food products and beverages), implemented in the less developed part of the country.

The ground for this strategy is the prevailing dependence of the rural region ( $I$ in Portugal) economy, with regard to its (international and moreover interregional) exports, on primary products, namely "products of agriculture, animals farming, hunting and related services". The idea is then to transform these products, generating more value added in the less developed region, and export them only in this more elaborated form i.e. as agri-food products. The simulation results, however, come to recognize a relative low effectiveness of this development strategy focused on the agri-food sector, either because the polarization of economic activity in the most developed region will eventually attract for itself a significant part of the benefits, or because the availability of agricultural products may be limited by land constraints. On a positive note, the methodological and policy implications concerning 
the consideration of resource-constrained products are a fundamental and innovative facet of the approach adopted in this research.

Of course, this work admits the need to find relevant counterforces to tackle the economic and social vulnerability of regions that are not positioned on the benefit side of the global logistics scale (Marsden and Sonnino, 2005). In other words, a shift from agricultural growth to rural development is required (Martinho, 2015), meaning a diversification of the economic base of those regions (Psaltopoulos et al., 2004). Agri-food products may be part of this diversification, despite the arguable limitations of this strategy. On the other hand, as an alternative or complementary strategy, it is possible to find alternative products that are not agriculture-based and that could have a far more significant impact on the local economy of a laggard region. This might be because such products must be produced where they are consumed (or they are intensive users of these non-tradable products), or because they depend neither on limited natural resources nor on products that use scarce natural resources intensively. The major advantage of products such as agri-foods is not so much the strength of their pulling effect on the local economy, but rather their potential marketability, which derives from the markets' tendency to regard products based on traditional regional resources as truly genuine and of higher quality.

Finally, this research suggests, albeit only in an exploratory way, that promising strategies specifically tailored to the specificity of region $I$ in Portugal may exist, which are superior to the strategy based on the development of endogenous-resource based sectors. One interesting example of such strategies would be to attract more former migrants (even if they are retired). According to the available indications, they are already returning to $I$ in significant numbers. There is the enhanced advantage that their consumption patterns greatly favour the type of products considered as nontradable, mainly personal services, this being the reason why these products have such an impact on I's local economy.

\section{References}

Barata, E., Cruz, L., Sargento, A., Ramos, P., Ferreira, J.-P. (2011). Deriving Regional Input-Output Matrices to Assess Impacts in Small Portuguese Peripheral Regions. In Cámara, A., Cardenete, M., Medina, A., Monrobel, J. (eds), Sectores estratégicos para un nuevo modelo económico. IV Jornadas Españolas de Análisis Input-Output, Universidad Rey Juan Carlos, Madrid.

de la Torre Ugarte, D., English, B., Jensen, K. (2007). Sixty Billion Gallons by 2030: Economic and Agricultural Impacts of Ethanol and Biodiesel Expansion. American Journal of Agricultural Economics 89 (5): 1290-1295. 
Hewings, G., Dridi, C., Guilhoto, J. (2005). Impacts of Reallocation of Resource Constraints on the Northeast Economy of Brazil. Paper Presented at the 45th Congress of the European Regional Science Association, Amsterdam, Netherlands - 23-27 August, 2005.

Hyytiä, N. (2014). Farm diversification and regional investments: efficient instruments for the CAP rural development targets in rural regions of Finland?. European Review of Agricultural Economics 41 (2): 255-277.

Hyytiä, N., Kola, J. (2013). Tourism Policy as a Tool for Rural Development. Applied Economic Perspectives and Policy 35(4): 708-730.

Hubacek, K., Sun, L. (2001). A scenario analysis of China's land use and land cover change: incorporating biophysical information into input-output modeling. Structural Change and Economic Dynamics 12(4): 367-397.

Hulu, E., Hewings, G. (1993). The Development and Use of Inter-regional Input-Output Models for Indonesia under Conditions of Limited Information. Review of Regional Development Studies 5: 135-153.

Irwin, E., Isserman, A., Kilkenny, M., Partridge, M. (2010). A century of research on rural development and regional issues. American Journal of Agricultural Economics 92(2): 522-553.

Jackson, R. (1998). Regionalizing National Commodity-by-Industry Accounts. Economic Systems Research 10 (3): 223-238.

Kronenberg, T. (2009). Construction of Regional Input-Output Tables Using Nonsurvey Methods: The Role of Cross-Hauling. International Regional Science Review 32(1): 40-64.

Kilkenny, M., Partridge, M. (2009). Export sectors and rural development. American Journal of Agricultural Economics 91(4): 910-929.

Lahr, M. (1993). A Review of the Literature Supporting the Hybrid Approach to Constructing Regional Input-Output Models. Economic Systems Research 5: 277-293.

Lindberg, G., Hansson, H. (2009). Economic impacts of agriculture in Sweden: a disaggregated inputoutput approach. Acta Agriculturae Scandinavica, Section C - Food Economics 6(2): 119-133.

Llano, C., Esteban, A., Pulido, A., Pérez, J. (2010). Opening the Interregional Trade Black Box: The C-intereg Database for the Spanish Economy (1995-2005). International Regional Science Review 33: 302-337.

Marsden, T., Sonnino, R. (2005). Rural development and agri-food governance in Europe: Tracing the development of alternatives. In Higgins, V., Lawrence, G. (eds) Agricultural Governance: Globalization and the new politics of regulation. Routledge, Taylor and Francis Group: 50-69.

Marsden, T., Sonnino, R. (2008). Rural development and the regional state: Denying multifunctional agriculture in the UK. Journal of Rural Studies 24(4), 422-431.

Martinho, V. (2015). Agricultural Economics in the Context of Portuguese Rural Development. In Martinho, V. (ed), The Agricultural Economics of the 21st Century. Springer International Publishing Switzerland: 121-136.

Martins, J., Marques, J., Castro, E. (2013). Estimating net migrations at regional and age-specific group levels. $52^{\text {nd }}$ ERSA Conference Proceedings, Palermo, Italy.

Miller, R., Blair, P. (2009). Input-Output Analysis - Foundations and Extensions. $2^{\text {nd }}$ Edition, Cambridge University Press, Cambridge, UK. 
Oosterhaven, J. (1984). A Family of Square and Rectangular Inter-Regional Input Output Tables and Models. Regional Science and Urban Economics 14: 565-582.

Pastor, J., Peraita, C., Pérez, F. (2015). Estimating the long-term economic impacts of Spanish universities on the national economy. Papers in Regional Science (doi:10.1111/pirs.12157).

Pereira, X., Carrascal, A., Fernández, M. (2011). Impacto Económico do Turismo Receptor através de Modelos Origem-Destino: Uma Aplicação para a Galiza. In Haddad, E., Ramos, P., Castro, E. (eds), Modelos Operacionais de Economia Regional. Princípia Editora, Cascais.

Polenske, K., Hewings, G. (2004). Trade and spatial economic interdependence. Papers in Regional Science 83: 269-289.

Psaltopoulos, D., Thomson, K., Efstratoglou, S., Kola, J., Daouli, A. (2004). Regional social accounting matrices for structural policy analysis in lagging EU. European Review of Agricultural Economics 31(2): 149-178.

Ramos, P., Barata, E., Pimentel, A. (2013). Um Modelo Input-Output Bi-Regional Litoral-Interior para Portugal: metodologia de construção e alguns resultados sobre a estimativa de comércio interregional. In Santos, J., St-Aubyn, M., Lopes, J., Santos, S. (eds), Livro de Homenagem a João Ferreira do Amaral. Almedina, Coimbra.

Ramos, P., Castro, E., Cruz, L. (2011). Economically Sustainable Demography: Reversing Decline on Portuguese Peripheral Regions. $19^{\text {th }}$ International Input-Output Conference. Alexandria, USA.

Ramos, P., Cruz, L., Barata, E., Parreiral, A., Ferreira, J-P. (2015). A Bi-Regional (Rectangular) InputOutput Model for Portugal: Centro and Rest of the Country. In Godinho, P., Dias, J. (eds), Assessment Methodologies: energy, mobility and other real world applications. Ch. 12 . Imprensa da Universidade de Coimbra, Coimbra, 265-285.

Roberts, D. (1998). Rural-urban interdependencies: Analysis using an inter-regional SAM model. European Review of Agricultural Economics 25(4): 506-527.

Roberts, D. (2000). The spatial diffusion of secondary impacts: rural-urban spillovers in Grampian, Scotland. Land Economics, 76(3): 395-412.

Roberts, D. (2005). The role of households in sustaining rural economies: a structural path analysis. European Review of Agricultural Economics 32(3): 393-420.

Robison, H. (1997). Community Input-Output Models for Rural Area Analysis with an Example from Central Idaho, Annals of Regional Science, 31: 325-351.

Robison, H., Lahr, M. (1997). The Effect of Bifurcation Error in Small Area Intercommunity InputOutput Models: An Example from North Central Idaho. Journal of Regional Analysis \& Policy, 27: 3-18.

Robison, H., Miller, J. (1988). Cross-Hauling and Nonsurvey Input-Output Models: Some Lessons from Small Area Timber Economies. Environment and Planning A 20: 1523-1530.

Sargento, A., Ramos, P., Hewings, G. (2011). Input-Output Modeling based on Total-Use Rectangular Tables: Is this a Better Way?. Notas Económicas 34:8-34.

van der Ploeg, J., van Broekhuizen, R., Brunori, G., Sonnino, R., Knickel, K., Tisenkops, T., Oostendie, H. (2008). Towards a framework for understanding regional rural development. In: van der Ploeg, J., Marsden, T. (eds) Unfolding webs: the dynamics of regional rural development. Assen, The Netherlands: Van Gorcum, 1-28. 
Zhang, F. (2007). Conservation reconsidered: a modified input-output analysis of the economic impact of China's land conservation policy. In Hupes, G., Ishikawa, M. (eds) Quantified Eco-efficiencyAn introduction with applications. Eco-Efficiency in Industry and Science Series Vol. 22, Springer, Dordrecht.

\begin{tabular}{lccccc}
\multicolumn{1}{c}{ ANNEX } \\
\end{tabular}

